\title{
HI-TECH LIBRARY WITH RFID AUTOMATION SYSTEM
}

\author{
Upasana \\ Assistant librarian \\ Sushant University, Gurgaon \\ upasana@sushantUniversity.edu.in
}

\section{Manuscript Info Abstract}

Manuscript History

Received: 08 December 2020

Final Accepted: 22 January 2021

Published: 10 February 2021

Online Published: March 2021

DOI: http:/ / dx.doi.org/10.35337/EIJLITR.2021.1305

(C) Upasana The Author. This is an open access article under the terms of the Creative Commons Attribution License 4.0, which allows use, distribution and reproduction in any medium, provided the original work is properly cited.

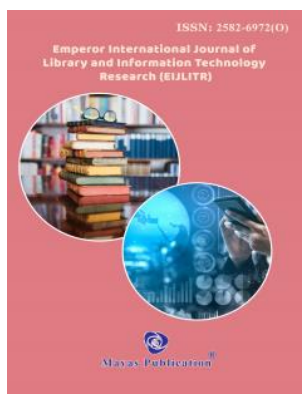

Before long a day, RFID is associated with the upkeep and security parts of the assets of the libraries. This paper considers the different bits of RFID Technology. Computerization has reevaluated the systems for libraries utilized by the partners and made consent to information and data less troublesome and speedier. RFID improvement is considered as top level progression being utilized in cutting edge's libraries. In the post-COVID-19 period, RFID changes into the extraordinary decision for chiefs as equipment like Gate, Kiosk, Book Drop and handheld Readers are basically important. This paper also uncovers the issues looked by the guardians.

Keywords: Radio Frequency Identification Technology, RFID, partners, Tags, Kiosk

\section{INTRODUCTION}

Radio intermittent ID (RFID) is a movement that maintains no view ID of things. Basic areas of a total RFID System for library kind of environment are Tags, Readers and library the board Systems. Executing RFID structures in libraries will help tasks like stream, re-racking and robbery obvious proof. It can either supplant or improve the current library normalized mark structure. Right when the cost of work is considered for an endeavor, for instance, enrollment, choice, stock holds records, mis-racked things, etc RFID can have wind up being particularly productive when stood separated from scanner name structures. To spread it out, RFID streamlines work measure in the zones of self-affiliation books return, rack the board, and stock.

RFID systems are joined names and perusers. Information is coded on a re-writable name which is contained a microchip and radio wire that is conveyed off a course station by techniques for a RFID peruser. Not in the slightest degree like normalized mark perusers' RFID System needn't sit around idly with "View" consequently 3-5 things can be taken a gander at and the security structure deactivated in one movement. 
RFID helps libraries with robotizing more than $90 \%$ unmistakably trades. This results in better relationship of staff resources for stay mindful of affiliation demands which achieve more unquestionable definitive advantage and an improved customer experience for library customers.

RFID improvement can be motorized in a library with around 25000 no's of books in about 4 consistently and a half. Each RFID Tag has a security cycle which is SET during take a gander at advancement and again RESET while choice trade. Any unapproved/thing being brought out in the library through RFID passages would trigger a general media alert.

Library Management Software can be converged with RFID structure using SIP2 or NCIP shows other than KOHA, SOUL 2.0, Liberty, TCS ION, NEWGENLIB, SLIM21, E-GRANTHALAYA, AUTOLIB, VTLS Virtua, LIBSOFT\& LIMSYYS.

\section{Definition}

RFID is an improvement used for electronic and eliminated ID of articles, individuals, and books.

RFID is that structure, which is secure of the book and non-book material; it is that system which gives various affirmations to different thing, articles, and thing.

As displayed by Dictionary.com Radiofrequency ID a headway that uses electronic names set on objects people, or the electronic peruser using radio waves.

\section{In COVID-19 RFID Technology}

Radiofrequency seeing check improvement is another age AIVC based progress that by and large redesigns the library adequacy $100 \%$ precision. RFID constantly gives the course and robbery measure. It helps the staff with achieving more worth added relationship for the customers.

> Social discarding can be followed by keeping a central segment from long queues.

$>$ No human contact library trade can be created.

> Patrons obvious evidence is possible inside the level of 5 to $7 \mathrm{cms}$ (No touch required)

$>$ Gate radio wire can replace the need of really checking any accomplice at the exit.

$>$ Inventory becomes contact free with help of a Handheld peruser.

Improvement of library relationship through RFID Technology

\section{Libraries}

Stock Management: Operations, for instance, supervising materials on the racks, finding things that are missing, and perceiving mis-resigned things are streamlined, and taking stocks reliably will be achievable.

Improved Patrons Service: Spending immaterial time on course exercises licenses library staff to help advocates. Routine ally organizations are not disturbed regardless, when libraries are going up against staff need and spending cuts.

Versatility and Modularity: The ability to add more state-of-the-art things and features as records and customer needs direct expenses of accepting the development can be regulated throughout some time. Thinks about organized financing and more effective usage of institutional spending plans.

Security: Library thing ID and security bit is joined into a lone tag, consequently discarding the need to associate an additional security strip, Hence, restricting naming time and its connected cost. Security bit is normally deactivated and reactivated as materials are taken a gander at and in; hence the same security procedures are required. 


\section{Library Staff}

Less time is needed for dispersal action. Executing RFID will altogether diminish the proportion of time expected to issue, get, transport, sort, and hold library materials. Automated enrollment will decrease staff time required for material managing.

\section{Capable Inventory Management}

Stock organization ought to be conceivable using a handheld peruser without closing the library and is on numerous occasions speedier diverged from the current normalized label based structure.

Reduce Repetitive Stress, Injuries: The RFID structure has decreased the monotonous sifting of the individual things at the stream work territory during enlistment similarly as enrollment and thusly avoids RSI like carpal entry problem. Putting confidence in a RFID-based structure doesn't require real de-racking a lot of library materials.

\section{Patrons}

Promoters will contribute less energy holding up hush-hush out lines by using self-enrollment, enlistment systems. Sponsors find what they are looking for quickly and with no issue. Updates for the due dates license sponsors to submit obtained materials on time. Usage of book drops \&returns for library material considers versatile timings. RFID-engaged ally cards consider straightforward advocate conspicuous evidence.

\section{RFID Technology over scanner label system}

$>$ Non-see examining of various things at the same time obliges powerful course of library materials.

$>$ Locating unequivocal things on racks is possible using RFID-based handheld perusers.

$>$ RFID-based systems can be conveniently joined with automated material dealing with (AMH) unit to scrutinize the moving things.

> On-chip data accumulating and reprogrammable memory grants RFID names to record information like the territory of books in the library, estimations, etc

$>$ Auto-area of unapproved things leaving the library premises is possible using RFID based structure.

$>$ RFID-based systems can be used in brutal conditions.

\section{Obtaining of the Hardware}

Sourcing of Hardware for instance Perusers, Tags and Antenna ought to be done before starting whatever else. At the point when the gear specific and individual things are settled, express read territories can be picked and execution ought to be conceivable.

Naming of Books: Each and every one book ought to be named. The cycle needs 2-3 people perseveringly adding names to a specific area on the books as picked before from the revelations during the pilot test.

Fusing Middleware: Integrating middleware with the current LMS and testing the results for updates and bungles

Performing Test Cases: Predefined sets of analyses will be acted in circumstance based association to take a gander at the unit level and structure level execution for precision and more critical all through.

Getting ready Staff: This piece of the execution will arranged staff for various pieces of RFID Technology and the new system set up. There will be a demo and instructional course that will recollect all of the cycles for the system.

Communication Improvement: The missteps and upgrades found from the investigations will be gotten back to upgrade the system execution. 


\section{Thing Requirement}

\section{Entryway Detection System (HFGA2/GA3)}

HFGA2 is an ISO-15693 reliable walk around entrance recognizable proof System prepared for distinguishing unapproved marked things going through it. It has an inbuilt general media prepared office for thievery disclosure and a base read extent of 36 inches.

\section{Staff Circulation Station(HFLB03)}

HFLB03 is a connection and-play multi-show gathering mechanical assembly peruser system exceptionally planned for library dispersal work zone applications. With a read range up to $25 \mathrm{~cm}$, it might be used for part of new books or borrowers and issue/return of books at the stream work territory.

\section{Self-Check in/Checkout Kiosk(HFLB021)}

HFLB021 is a free multi-show Self Check-in/Check-out stand generally for oneself issue and return of books in a library. With its inbuilt screen and printer, advocates can view and print trade related information like gave, surprising fine (expecting to be any, etc Redone information can in like manner be engraved on the trade slip.

\section{Book Return Station (HFBD01)}

HFBD01 is a touchscreen-based multi-show book drop essentially used for returning library books. It helps in better stream and gives time versatility to allies for returning the gave material.

\section{HF Hand held reader (HFHH3)}

HFHH3 is a fundamental handheld peruser essentially expected for performing works out, for instance, rack demand checking. Rack Reading, looking, stock analyzing in library kind of environment.

\section{RFID Tags (HIFT01)}

HFT01 are rewritable latent HF marks working on $13.56 \mathrm{MHz}$ repeat. Open in various types and construction factors these are used for naming library materials to astoundingly recognize explicit marked things using the RFID-based robotized library Management System.

\section{Sharp Cards (HFS0101)}

HFSM01 are standard 1k MIFARE development based contactless sharp cards used for various applications, for instance, Identity cards, laborer cards, access control, and holder cards.

\section{RFID Architecture}

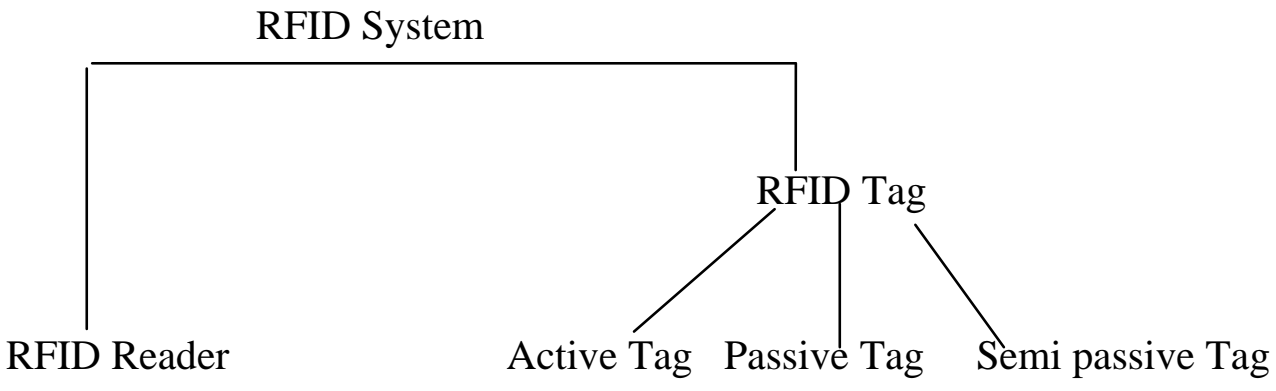

RFID structure contains two sections RFID peruser and RFID Tag. RFID Tags are can be various sorts. It might be dynamic tag, disconnected tag, and semi-idle tag. These segregated names don't have their power supply. hence, this uninvolved tag relies upon the radio ways which is coming from the RFID peruser for the wellspring of energy. while in case of semi-uninvolved name they used to have their power supply yet for conveying the analysis message back to the RFID peruser they used to rely upon the sign which is coming from the RFID peruser, while because of dynamic mark they used to have their power supply, But for imparting the sign back to the peruser they are relying on their power supply 
along these lines, as this disengaged tag doesn't have their power so the compass is less when appeared differently in relation to the dynamic and semi-unapproachable tag...

\section{Working Frequency}

LF: Low-repeat band

HF: High-Frequency band

UHF: high-repeat band

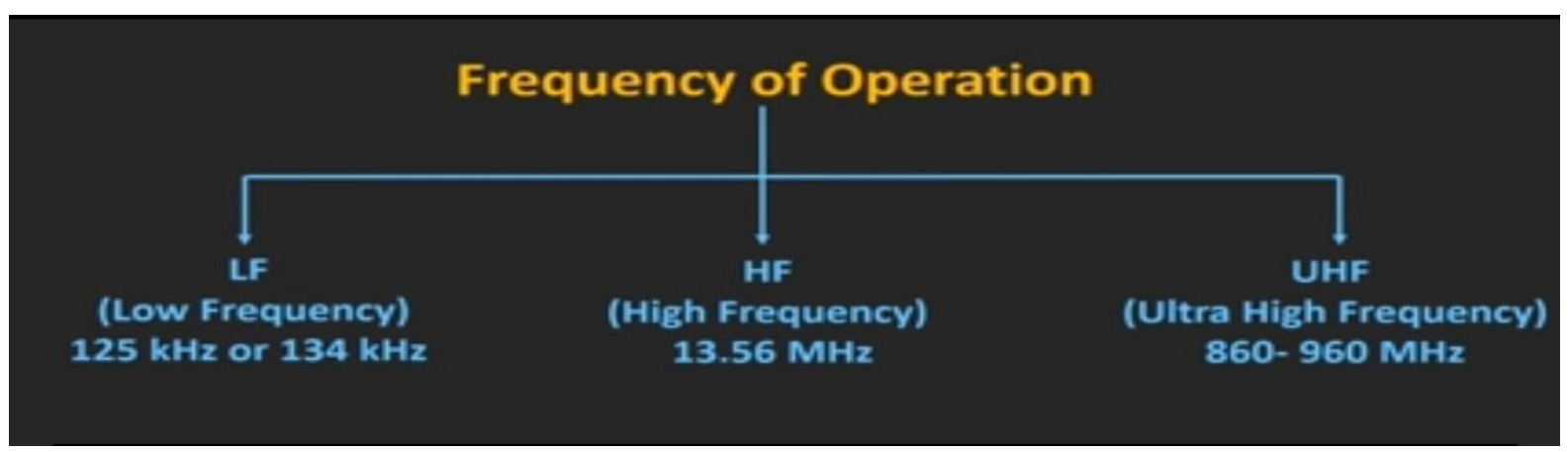

RFID can be of a gigantic number. The peruser is a RF signal generator. So this RF signal generator creates the radio waves which are imparted using this recieving wire. moreover to get the info signal which is coming from the name the RFID peruser similarly has an authority of the sign identifier and to manage the information which is being sent by the RFID tag, this RFID peruser also has a microcontroller or normally this RFID peruser is directly connected with the PC. An enormous part of the marks are used today is reserved name Passive names are extremely more affordable when diverged from the unique label similarly as they needn't bother with any force source so they are really diminished. Standoffish marks are coming in various constructions. These names could be a key size or could be of Mastercard size.

\section{Working Principle}

RFID names working rule relies upon the electromagnetic coupling if there ought to be an event of low repeat and the high-repeat peruser relies upon the inductive coupling, so the field which is made by this RFID peruser used to get with the recieving wire of a RFID tag and considering the regular coupling, the voltage will get affect across the twist of RFID tag. By and by a segment of the pieces of this voltage is getting reviewed and used as a power supply for the controller similarly as the memory segments Now as the RFID peruser is sending radio surges of a particular repeat so the voltage that is started across the twist is also of a particular repeat so this prompted voltage is moreover to drive the synchronized clock for the controller so now expecting we partner a load across the circle, current will start streaming this pile and if we change the impedance of the stack, the current that is flowing through this store will in like manner get changed

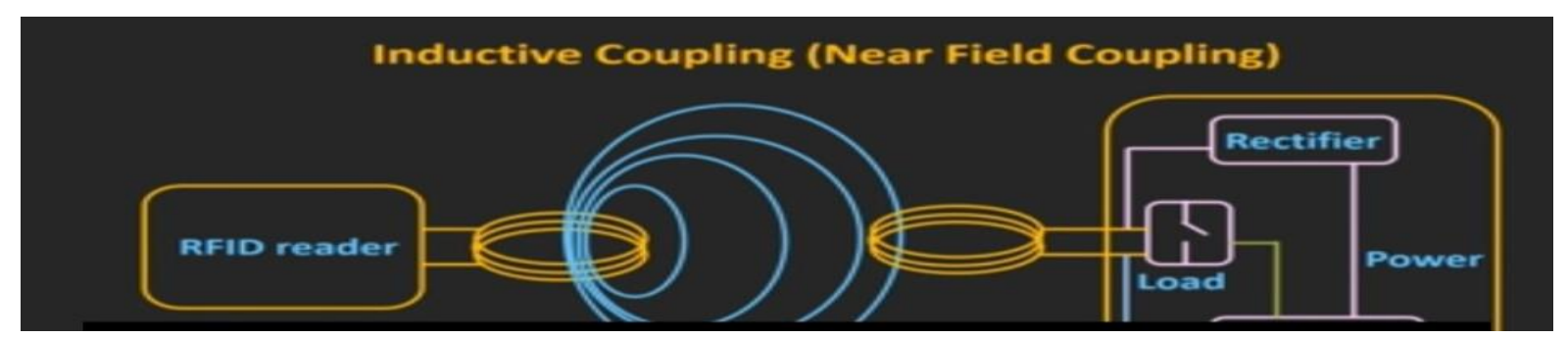

Expect if we switch on and off this load and the current will moreover get turned on and off. So this trading of current or speed of progress of current in like manner makes a voltage in a RFID peruser so this killing on and the pile is known as weight guideline. so now expect if this switch on and off this pile as demonstrated by the data that is taken care of inside the RFID name then that data can be examined by the RFID peruser as a voltage subsequently, in this way this store guideline we are changing the voltage that is delivered across the RFID peruser twist and in this way we are making the change on carrier 
repeat so as such a low repeat and high-repeat RFID marks using this stack balance method the data is being sent back to the RFID peruser. for excessively high repeat as a distance between the peruser and the tag is up two or three meters so the coupling between the peruser and the circle will be fire field coupling so RFID peruser incessantly sending the radio surges of a particular repeat towards the tag and in this response, this tag is passing on a feeble message to the RFID peruser now this slight sign which is being sent back to the RFID peruser is known as the backscattered signal and the power of this backscattered signal depends on the store organizing across the twist. If the pile organizing decisively, the power of the backscattered sign will be more. Notwithstanding, if the stack doesn't organize unequivocally, the force of this backscattered sign will be less. so thusly by changing the condition of a stack we can change the power of this backscattered signal and in case we change the condition of a store according to the data that is being taken care of across the RFID mark then that data can be sent back to the RFID peruser so as such RFID peruser prepared to distinguish that data. As of now in case of an unbelievable coupling as the distance between the RFID peruser and tag isn't numerous meters so the fundamental sign which is being sent by the peruser should be strong so the backscattered sign can be recuperated by the RFID peruser. So this is the way for a circumstance of a far-field coupling the sign is sent back to the RFID peruser using this backscattered change technique

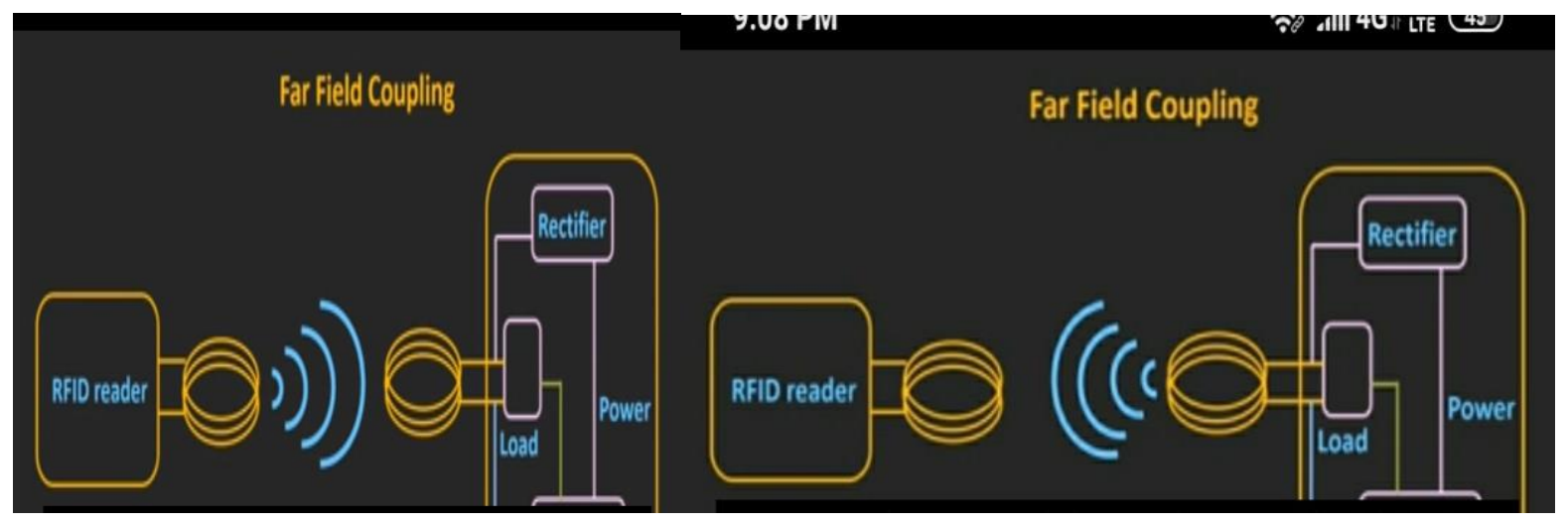

Practical issues faced during the implementation of RFID Technology in libraries

$>$ Hardware and Software ought to fulfill the Global proposed rule for use of RFID in libraries.

$>$ RFID hardware thing should be practical with overall shows, for instance, SIP2, NICP, ISO 180003, ISO15693, ISO14443A and ISO28560

$>$ The vender should make the gear and programming redesigns later on to acclimate to standard

$>$ Special highlight should be on Staff planning, Local assistance and vendor assurance.

$>$ In libraries13.56 MHz high-repeat marks should be used.

$>$ RFID marks for libraries should be reserved.

$>$ The ordinary read extent of the Tag for library application should not be extended fundamentally past the current extent of 8-20 creeps for more humble marks later on.

> Only marks including standardized EAS\& AFI features should be used in libraries.

$>$ The system will cause no check with various applications.

$>$ The System will utilize ISO/IEC18000-3mode1 name altered with the objective that they should work for the unmistakable verification of things in various libraries.

$>$ Security execution for RFID in libraries should not jolt a protesting of any security likelihood (EAS, AFI, Virtual Deactivation)

$>$ RFID should reprogrammable for migration purposes.

\section{Pros \& Cons. Of RFID System}

$>$ Speedy and basic customer self - charging and delivering

$>$ Reliability

$>$ High speed assessing

$>$ Automated material managing

$>$ Tag life

$>$ Self-organization, self-issue, self-return

$>$ Stock the chiefs 
$>$ Staff saving

$>$ Reducing Repetitive pressing factor wounds

$>$ Less time needed for stream movement

Cons.

$>$ High cost

$>$ Accessibility to settle

$>$ Removal of uncovered names

$>$ Exit doorway sensor (issue) issue

$>$ Invasion of customer insurance

$>$ Reader crash

$>$ Tag crash

$>$ Lack of standard

\section{Benefits of RFID Technology Implementation}

$>$ The imperative benefits of using RFID Technology execution in libraries are:

$>$ Quick and Efficient Circulation Operations.

$>$ Improved Security for library Items

$>$ Steady Inventory Management

$>$ Emerging Technology and Experience for Library Staff and Patrons.

\section{CONCLUSION}

With the usage of RFID advancement, customers can use the library organization $24 \times 7$. Self enrollment is possible. It maintains the scattering system enough. Allies don't need to stay in lines for issues and returned the books. They can issue and return the books at whatever point with the help of touch screen PCs. It constructs the capability, sufficiency, execution, and organization of the library. RFID and libraries can make contemplates in achieving the fortifying of the two customers and caretakers. Disregarding the way that RFID is expensive, still it has yielded surprising results for certain libraries concentrated out the world. It has the capacity of making the organization measures in the library more accommodating. The solitary limit in the journey is its tremendous cost, yet every new development execution is dearer. Also, RFID advancement prompts basic venture assets in staff cost, improves organization, and gives a capable result which prompts full affirmation security and access control. It not simply gives the consistent update of the library arrangement, authentic holding the chiefs yet moreover accomplishes progressing organizations.

\section{REFERENCE}

1. Bansode, S. also, Desale, S. (2009).Implementation of RFID Technology in University of Pune Library Program: Electronic library and Information Systems, 43(2), 20122014.doi:10.1108/003303309109. Recuperated on 21/01/2021

2. Coyle,K.(2005).Management of RFID in Libraries. Journal of Academic Librarianship, 31. 486489.retrived from library and information science and altered works informational index, recuperated on 21/01/2021.

3. Kotecha, Dhaval H. (2008). Automation in library using RFID Technology. Paper circulated in the techniques of 6th CALIBER-2008. Nagaland University Nagaland. recuperated on 23/01/2021.

4. Otondo, R.F., et al., Managerial basic intuition in the gathering of Radio Frequency Identification Technologies. European Journal of Information Systems, 2009. 18(6): p. 553-553-569. recuperated on $24 / 01 / 2021$.

5. Pallud, J. moreover, E. Monod, User experience of display progressions: the phenomenological scales. European Journal of Information Systems, 2010. 19(5): p. 562-580.

6. 6. Zhang, H., L. Liu, and T. Li, Designing IT structures as demonstrated by biological settings: A fundamental examination framework. The Journal of Strategic Information Systems, 2011. 20(1): p. 80-95.

7. The Chamber Dictionaryu.10th New Delhi : Alliied Cambers limited p. 1309. 
8. Lib. Best.www.RFID-library.com recuperated on 21/01/2021.

9. Mosak, Arun and Singh: Sonal (2013) Radio repeat unmistakable verification advancement (RFID) structure for the library."Redesign libraries in mechanized period, Daya Publishing House New Delhi. recuperated on 21/01/2021.

10. http://www.cinanthapuri.com recuperated on 21/01/2021.

11. http:// www.rfidlibrary.com recuperated on 21/01/2021.

12. http://www.rfiduu.com recuperated on 21/01/2021.

13. www.you tube recuperated on $21 / 01 / 2021$.

14. across, 6

15. current, 6

16. making, 8

17. RFID, 6

18. set aside, 6

19. UPASANA. (2021). RFID. IJMRT (p. 15 ). DELHI: REUH.

20. application RFID development 